\title{
Dependencies and systemic risk in the European insurance sector: New evidence based on Copula-DCC-GARCH model and selected clustering methods
}

\author{
Anna Denkowska, Stanisław Wanat
}

\begin{abstract}
A B S T R A C T
Objective: The objective of this article is to study the correlations between the most important European insurers and their participation in systemic risk in the insurance sector. We compare systemic risk in different market regimes.

Research Design \& Methods: We use statistical clustering methods for time units (weeks) to which we assign conditional variances obtained from the estimated CopulaDynamic Conditional Correlations-Generalised Auto-Regressive Conditional Heteroskedasticity model (C-DCC-GARCH). In each of the identified market regimes we determine the Conditional Value at Risk CoVaR systemic risk measure.
\end{abstract}

Findings: In this article we show a positive correlation of all the insurance companies under consideration. During global market crises the correlation appears stronger than in 'normal times.' This confirms that the insurance sector generates systemic risk in the presence of turbulences on financial markets, since the value level of the compared index CoVar is much higher in these conditions.

Implications \& Recommendations: Our research confirms the insurance sector's contribution to Systemic Risk. Thus, it is important to develop an analysis of systemic risk with a particular attention to the evolution of risk in time and the institutions' interconnectedness in the context of contagion using also some new modelling tools.

Contribution \& Value Added: A novel approach of this article is the analysis of dependencies in the insurance sector using the C-DCC-GARCH model with taxonomic methods.

\begin{tabular}{ll}
\hline Article type: & research article \\
Keywords: & systemic risk; insurance market; Copula-DCC-GARCH(C-DCC-GARCH) \\
JEL codes: & G22, C38, C32 \\
\hline
\end{tabular}

\section{Suggested citation:}

Denkowska, A., \& Wanat, S. (2020). Dependencies and systemic risk in the European insurance sector. New evidence-based on Copula-DCC-GARCH model and selected clustering methods. Entrepreneurial Business and Economics Review, 8(4), 7-27. https://doi.org/10.15678/EBER.2020.080401 


\section{INTRODUCTION}

This article is an answer to the 2017 European Insurance and Occupational Pensions Authority (EIOPA 2017) report that recommends the analysis of systemic risk in the insurance sector; i.e. undesirable financial occurrence with systemic cause and negative global effect in real economy (Eling and Pankoke, 2014 provide 43 definitions of systemic risk). The report pays special attention to two aspects: firstly, the evolution of risk over time and, secondly, dependencies among institutions. In an era of economic globalisation, one of the most important questions is the possibility of financial risk contagion. The higher the level of correlation among insurers, the greater the risk.

Therefore, we aim (i) to analyse systemic risk dynamics for the years 2005-2018, and (ii) to show precisely the interconnectedness among insurers and confirm their impact on systemic risk. The second point comes to the fore through the identified market regime during the largest turbulences on financial markets due to the financial crisis of 2007-2009.

Following the financial crisis of 2007-2009 and the European public debt crisis in 20102012 , interest in systemic risk has been significantly growing. Among other things, this resulted in the literature proposing many new methods for the study of financial institutions' influence on systemic risk. Moreover, both the academic community and financial regulatory authorities began to pay more attention to the role played by non-bank financial institutions, in particular insurance companies, in creating systemic risk. Before the crisis, most scholars generally accepted that the insurance market has a negligible impact on systemic risk. However - although many a study still supported the latter point of view - the recent literature offers several articles suggesting the possibility of the insurance market itself creating systemic risk. Let us quote here from a few articles whose authors claim that insurance companies:

- generate systemic risk (Billio, Getmansky, Lo, \& Pelizzon, 2012; Weiß \& Mühlnickel, 2014),

- can be systemically important when they conduct investment activities outside of their normal insurance busines (Baluch, Mutenga, \& Parsons, 2011; Cummins \& Weiss, 2014), while in general the systemic significance of the insurance sector as a whole is still subordinated to the banking sector (Chen et al., 2013; Czerwińska, 2014),

- are systemically unimportant due to the low level of interconnections and the lack of strong dependence on external funding (Harrington, 2009; Bell, 2009; Keller, 2009; Geneva Association, 2010).

On the other hand, after studying a very large sample of insurers in a long-term horizon, Bierth, Irresberger and Weis (2015) claim that the level of generating systemic risk by the insurance sector is rather low, its peak having been reached during the financial crisis of 2007-2009. Moreover, these authors indicate the four L's - linkages, leverage, losses, liquidity - as the crucial factors influencing the exposure of insurers to systemic risk.

The present article belongs to the mainstream of studies in the linkages among large insurance companies and their participation in systemic risk in the insurance sector. Our main aim is to check whether the strength of existing connections among the eight largest insurers depend on the insurance market regime. These eight companies come from the list of the most important insurance companies in the world with respect to total assets five from Europe, one from the USA, Canada, and China - together with their participation 
in systemic risk in the European insurance sector. The market regimes are identified by analysing the weekly rates of return of the insurers in question during the period between January 2005 and December 2018. They are assessed using statistical clustering methods of time units (weeks) to which we assigned conditional variances obtained from the estimated C-DCC-GARCH model. Indeed, we assume that the change (increase) of the risk (variance) is a good and classical index of the financial market tension. Such an approach has the advantage that there is no need to assume a priori a number of market regimes, because this number is identified by the clustering quality assessment. Next, in each of the identified regimes we establish the CoVaR systemic risk measure, commonly used today (see e.g. Acharya, Pedersen, Philippon, \& Richardson 2010; Bierth et al., 2015; Jobst, 2014). We assume that the European insurance market is represented by the weekly rates of return from the STOXX 600 Europe Insurance index. The CoVaR measure, indicating the participation of each of the insurers to systemic risk, is assessed using the conditional distributions obtained from eight bivariate C-DCC-GARCH models. In each of these models one boundary distribution represents the European insurance market - on the logarithmic return from the stock market index STOXX 600 Europe Insurance index - while the other one represents the insurer, on the appropriate logarithmic rate of return. To the best of our knowledge, such an approach has not been used in systemic risk analysis ever before.

The paper consists of five chapters. The second one overviews the literature devoted to systemic risk in the insurance sector, the third chapter presents the methodology together with empirical results, the fourth one shows the data and describes our findings, whereas the fifth and last one proposes conclusions.

\section{LITERATURE REVIEW}

Let us begin with recalling the natural definition of systemic risk as 'any set of circumstances that threatens the stability of or public confidence in the financial system' (Billio et al., 2012).

Usually, systemic risk is endogenous, i.e. coming from the financial system itself, which amplifies its exogenous version. Systemic risk can be viewed as a coordination failure. The specific sources of systemic crisis are contagion, bank run, or liquidity crisis. Up to now, insurance has virtually been immune to systemic risk, which is partly explained by pyramidal risk sharing - which removes a lot of contagion risk - and less room for coordination failure than in other financial institutions. However, as insurance companies become increasingly involved in other financial activities or - rather - as insurance is increasingly often conducted by financial institutions that do not specialise only in this sector, the situation may well change. Of course, there are other causes that may lead to this, such as e.g. more pervasive liquidity insurance offer by the companies. In particular, these conclusions can be found in the special report by the Geneva Association (2010), 'Systemic risk in insurance: An analysis of insurance and financial stability'. Furthermore, Billio et al. (2010) already mention the growing interrelations between the insurance, banking, and hedge funds sectors as one of the causes of increasing systemic risk.

Another question is how to measure systemic risk, as several approaches are possible. Leaving this question aside for the moment - as the matter is raised in many of the articles mentioned below (e.g. Bernardi \& Catania, 2015) - let us quick overview at recent approaches to systemic risk in insurance. The general and most widespread view is that, for various reasons, the added value of insurance sector to systemic risk - whatever 
its definition and measurement tools - is very low but this recently undergoes a change, as the insurance market keeps evolving (also cf. the 2015 'Report on systemic risks in the EU insurance sector' by ESRB, 2015).

Indeed, Kanno (2016) observes that - contrary to the interbank market - the insurance market does not contain feedback mechanisms that would make it fully interconnected. However, Kanno indicates that interconnectedness in the insurance sector has not been explored yet with network theory or contagious default approach. As a conclusion, Kanno upholds the opinion of International Association of Insurance Supervisors (IAIS, 2011) that the degree of interconnectedness within the (re)insurance sector is small, which adds to its immunity to systemic risk. However, an earlier study (Dungey, Luciani, \& Veredas, 2014) notes that insurance companies display substantial systemic risk via interconnectedness with the financial sector and the real economy. Similarly, Bierth, Irresberger, and Weiß (2015) studied the contribution of 253 international life and non-life insurers to global systemic risk in 2000-2012, and they observe that systemic risk in the international insurance sector is small in comparison to that of banks. Still, during the financial crisis, insurers significantly contributed to the instability of the financial sector. In conclusion, the various factors determining the systemic risk of insurers are interconnectedness, leverage, loss ratios, and the insurer's funding fragility. Bierth, Irresberger, and Weiß (2015) furthermore conclude that there is no big difference in the contribution to global systemic risk between life insurers and non-life insurers. In particular, there seems to be no relationships between an insurer's size and its contribution. The authors support the viewpoint that unlike the banking sector, the insurance one predominantly suffers from exposition to systemic risk, rather than from the financial system's fragility. Moreover, another study (Mühlnickel \& Weiß, 2015) indicates a strong positive relationship between consolidation in the insurance industry and moderate systemic risk in the insurance sector, but definitely no extreme systemic risk. Similar conclusions are drawn by Berdin and Sottocornola (2015), who use three measurements to infer that the insurance industry has a persistent systemic relevance over time but far from the role of banks in causing systemic risk compared to banks. An interesting contrast between the Eurozone and the USA is observed by Bernal, Gnabo, and Guilmin (2014), who surmise that in 2004-2012, the other financial services sector and the banking sector in the Eurozone contribute relatively more to systemic risk in periods of distress than the insurance sector, while in the USA the insurance industry is systemically the riskiest financial sector.

These recent results were preceded by several articles - many of them triggered by the AIG's collapse in the recent crisis - in the years 2009-2013 (as listed in the excellent survey by Eling and Pankoke, 2014). Harrington (2009) claims that traditional insurance products make no contribution to systemic risk. Radice (2010) comes to a two-fold conclusion. He identified those phenomena that do not contribute to generating SR; According to him, these are the unavailability of insurance, life insurance, insolvency of CDS and the use of credit ratings. He indicated those that may be systemically risky, i.e. contagion with assets, limited fungibility of the available liquidity of the group, difficulties in unregulated / uninsured activity within the insurance group.

Baluch, Mutenga, and Parsons (2011) noted that the increase in systemic risk in the insurance sector has been caused in recent years by an increased share in capital markets and the introduction of banking services. 
The same year, van Lelyveld, Liedorp, Kampman van Lelyveld, Liedorp and Kampman (2011) studied contagion and the contribution of linkages among insurers and reinsurers to systemic failure, which leads them to conclude that the collapse of several reinsurers would result in the bankruptcy of only a few primary insurers.

That is, these authors suggest that the potential failure of one or more (re)insurers is not a systemic risk. Still, in 2011, a study of the US insurance sector was performed by Cummins and Weiss (2014a), which shows that the largest contributors to SR are non-traditional and non-insurance activities such as derivatives trading and financial guarantees.

Grace (2011) states that the situation in the insurance sector is different from that in the banking sector; the duration of assets and liabilities are more closely matched.

Similarly, Kessler (2013) asserts that reinsurance does not contribute to systemic risk, while Baur, Enz, and Zanetti (2003) come to the same conclusion. On the other hand, Mühlnickel and Weiß (2014) claim that the insurance sector is sensitive to the financial system's deterioration and contributes to systemic risk.

Schwarcz and Schwarcz (2014) concentrate on systemic risk in insurance as resulting from correlations among firms.

Our work responds to the problems still open in literature (Brechmann et al., 2013; Reboredo \& Ugolini, 2015; Di Bernardino et al., 2015) regarding the analysis of the insurance sector in the context of interrelationships and systemic risk along with SR measures (Barrieu et al., 2014; Tang \& Yang, 2012). We undertake research both in the context of searching for a model and assessing whether and at what level SR is generated during the normal state of the market and during turbulences. We analyse eight insurance companies from the list of the most important insurance companies in the world ranked by total assets, five of which are the largest in Europe, two in North America, and one in Asia. Thus, we propose the following research hypotheses:

1. All analysed insurers generate systemic risk in the European insurance sector regardless of the country, currency, and the size of insurer measured by the size of assets.

2. The systemic importance of the European insurance market is the same for all insurers, except for the Chinese, for whom it is less important (CoVaR is higher). During turbulences, the SR generation level is much higher than in the normal state.

3. The existence of strong relationships between insurers and the European insurance sector results in a higher SR level.

In order to verify the hypotheses, an innovative hybrid approach has been used, which combines machine learning cluster analysis with the C-CDD-GARCH model. We used the C-DCC-GARCH model (Di Clemente, 2018; Karimalis \& Nomikos, 2018; Oh \& Patton, 2018; Gaizner, 2019) in three different contexts:

- in combination with cluster analysis methods to determine market states which - as far as we know - has not been described in literature up to now,

- to determine conditional correlations between insurers,

- to calculate the CoVaR risk measure.

\section{RESEARCH METHODOLOGY}

The empirical strategy we use in this article to analyse the dependences and assess systemic risk on the European insurance market consists of two basic steps: 
1. Market regime identification;

2. Analysis of identified market regimes:

- dependences among the studied insurance companies,

- correlations between a given insurance company and the European insurance market as represented by the STOXX 600 Europe Insurance index,

- systemic risk.

It is assumed in the first step that market regimes are identified using statistical methods of grouping weekly periods $t$ according to the assigned conditional variances of rates of return of all the instruments under analysis. The conditional variances that are essential in this approach are obtained through the multivariate C-DDC-GARCH model. In this model, the distribution of the rates of return vector $r_{t}=\left(r_{1, t}, \ldots, r_{1, t}\right)^{\prime}$ - conditional with respect to the set $\Omega_{t-1}$ of information available up to the moment $t-1$-is modelled using the conditional copula proposed by Patton (2006). The copula assumes the following form:

$$
\begin{gathered}
r_{1, t}\left|\Omega_{t-1} \sim F_{1, t}\left(\cdot \mid \Omega_{t-1}\right), \ldots, r_{k, t}\right| \Omega_{t-1} \sim F_{k, t}\left(\cdot \mid \Omega_{t-1}\right) \\
r_{t} \mid \Omega_{t-1} \sim F_{t}\left(\cdot \mid \Omega_{t-1}\right) \\
F_{t}\left(r_{t} \mid \Omega_{t-1}\right)=C_{t}\left(F_{1, t}\left(r_{1, t} \mid \Omega_{t-1}\right), \ldots, F_{k, t}\left(r_{k, t} \mid \Omega_{t-1}\right)\right)
\end{gathered}
$$

in which $C_{t}$ denotes the copula, whereas $F_{t}$ and $F_{i, t}$ are the multivariate CDF and the CDFs of the marginal distributions at time $t$. In general, the univariate rates of return $r_{i, t}$ can be modelled by various specifications of the mean model, e.g. the ARMA process (Box \& Jenkins, 1970) and various specifications of the variance model e.g. sGARCH, fGARCH, eGARCH, gjrGARCH, apARCH, iGARCH, csGARCH (Fiszeder, 2009).

In our study, the following ARMA process is applied to all the series of returns for the mean:

$$
\begin{gathered}
r_{i, t}=\mu_{i, t}+y_{i, t}, \\
\mu_{i, t}=E\left(r_{i, t} \mid \Omega_{t-1}\right), \mu_{i, t}=\mu_{i, 0}+\sum_{j=1}^{P_{i}} \varphi_{i j} r_{i, t-j}+\sum_{j=1}^{Q_{i}} \theta_{i j} y_{i, t-j}, \\
y_{i, t}=\sqrt{h_{i, t}} \varepsilon_{i, t},
\end{gathered}
$$

While for the variance we use the eGARCH model (Nelson, 1991):

$$
\log \left(h_{i, t}\right)=\omega_{i}+\sum_{j=1}^{p_{i}}\left(\alpha_{i j} \varepsilon_{i, t-j}+\gamma_{i j}\left(\left|\varepsilon_{i, t-j}\right|-E\left|\varepsilon_{i, t-j}\right|\right)+\sum_{j=1}^{q_{i}} \beta_{i j} \log \left(h_{i, t}\right),\right.
$$

In which $\varepsilon_{i, t}=y_{i, t} / \sqrt{h_{i, t}}$, are independent random variables with the same distribution. In the empirical analysis we considered the following distributions: normal, skew-normal, t-Student, skew-t-Student and GED.

The structure of the dependences between the rates of return is modelled using elliptic copulae with conditional correlations $R_{t}$ as parameters, the dynamics of which is described by the $\operatorname{DCC}(m, n)$ model:

$$
\begin{gathered}
H_{t}=D_{t} R_{t} D_{t} \\
D_{t}=\operatorname{diag}\left(\sqrt{h_{1, t}}, \ldots, \sqrt{h_{k, t}}\right), \\
R_{t}=\left(\operatorname{diag}\left(Q_{t}\right)\right)^{-\frac{1}{2}} Q_{t}\left(\operatorname{diag}\left(Q_{t}\right)\right)^{-\frac{1}{2}}, \\
Q_{t}=\left(1-\sum_{j=1}^{m} c_{j}-\sum_{j=1}^{n} d_{j}\right) \bar{Q}+\sum_{j=1}^{m} c_{j}\left(\varepsilon_{t-j} \varepsilon^{\prime}{ }_{t-j}\right)+\sum_{j=1}^{n} d_{j} Q_{t-j},
\end{gathered}
$$


in which the conditional variances $h_{i, t}$ are modelled using univariate $\operatorname{GARCH}(p, q)$ processes of the form (7), $\varepsilon_{t}=D_{t}^{-1} y_{t}, y_{t}=\left(y_{1, t}, \ldots, y_{k, t}\right)^{\prime}$ and $\bar{Q}$ is the unconditional covariance matrix of standardised residuals $\varepsilon_{t}$. In the specification (11) $c_{j}(j=1, \ldots, m), d_{j}(j=$ $1, \ldots, n)$ are scalars describing the influence on the current correlations of the respective previous shocks and previous conditional correlations.

The parameters of the C-DCC-GARCH model above are estimated using the inference function for margins - IFM. This method is presented in detail e.g. in Joe (1997). The computations were done in the R environment using the 'rmgarch' package developed by Ghalanos (2019).

We used statistical methods of unsupervised classification in order to identify market regimes. We assumed that the groups obtained from periods $t$ have similar levels of risk, i.e. have a similar conditional variance. The clustering was performed by means of hierarchical methods in which groups are created recursively by connecting the most similar objects (Ward's method). We also used two division methods, i.e. the classical k-means method and the partitioning around medoids method (PAM) proposed by Kaufman and Rousseeuw (1990). The optimal number of groups - and thus the market regimes - were assessed under the following measures of cluster validity: the Calinski-Harabasz index (Calinski \& Harabasz, 1974), the silhouette index-SI (Kaufman \& Rousseeuw, 1990), the Dunn index (Dunn, 1974), and the Xie-Beni separation measure (Xie \& Beni, 1991).

In the second stage of analysis, in each of the identified market regimes we assessed the CoVaR. The systemic risk measure $\operatorname{CoVaR} R_{\beta, t}^{i \mid j}$ was defined to be the value at risk $(\mathrm{VaR})$ of the institution (market index) $i$ under the condition that another institution (market index) $j$ is subject to distress, i.e. its rate of return is smaller than its value at risk, meaning that:

$$
P\left(r_{i, t} \leq \operatorname{CoVaR}{ }_{\beta, t}^{i \mid j} \mid r_{j, t} \leq \operatorname{VaR}_{\alpha, t}^{j}\right)=\beta,
$$

Using the conditional probability formula we received:

$$
\frac{P\left(r_{i, t} \leq \operatorname{CoVaR}_{\beta, t}^{i \mid j}, r_{j, t} \leq \operatorname{VaR}_{\alpha, t}^{j}\right)}{P\left(r_{j, t} \leq V a R_{\alpha, t}^{j}\right)}=\beta,
$$

The definition of the value at risk for the institution $j$, i.e. $\operatorname{VaR}_{\alpha, t}^{j}$ yielded $P\left(r_{j, t} \leq \operatorname{VaR}_{\alpha, t}^{j}\right)=\alpha$, that is:

$$
P\left(r_{i, t} \leq \operatorname{CoVaR}_{\beta, t}^{i \mid j}, r_{j, t} \leq \operatorname{VaR}_{\alpha, t}^{j}\right)=\alpha \beta .
$$

Therefore, the assessment of $\mathrm{CoVaR}_{\beta, t}^{i \mid j}$ required the knowledge of bivariate distribution $F_{t}$ of the vector $\left(r_{i, t}, r_{j, t}\right)$. Due to the Sklar Theorem, this distribution can be represented using the copula in the following way:

$$
F_{t}\left(r_{i, t}, r_{j, t}\right)=C_{t}\left(F_{i}\left(r_{i, t}\right), F_{j}\left(r_{j, t}\right)\right) \text {. }
$$

Invoking (15), $\operatorname{CoVaR} R_{\beta, t}^{i \mid j}$ can be determined by (numerically) solving the equation:

$$
C_{t}\left(F_{i}\left(\operatorname{CoVaR}_{\beta, t}^{i \mid j}\right), \alpha\right)=\alpha \beta .
$$

In the empirical analysis, we studied the influence on the European insurance market's systemic risk of the five largest insurance companies from Europe and the biggest 
insurers from the USA, Canada, and China. We assumed that $r_{i, t}$ represents the European insurance market (we made use of the weekly rates of return from STOXX 600 Europe Insurance), while $r_{j, t}$ describes the insurers (we made use of the weekly logarithmic returns on shares). For each of the eight pairs - the rate of return from the STOXX 600 index $r_{i, t}$, logarithmic return of the insurer $r_{j, t}$ - we assessed parameters of the bivariate C-DCC-GARCH model described by the formulae (1)-(7). Then, using these parameters together with the conditional correlations obtained by these models, we determined the copula $C_{t}$ and the distributions $F_{t}$. The values $\operatorname{CoV} a R_{\beta, t}^{i \mid j}$ for the analysed period were obtained by solving numerically the equation (16).

\section{RESULTS AND DISCUSSION}

From the literature analysis, we conclude that much was already written about the generation of SR in the insurance sector, and the conclusions are divided. Baluch, Mutenga, and Parsons (2011) and Schwarcz and Schwarcz (2014) confirm the thesis that the insurance sector generates SR, especially in the recent period, when insurers have expanded non-insurance activities. From our case study of the eight largest insurers, we conclude that each insurance company generates SR. In addition, the SR level increases during turbulences on financial markets. Many works (e.g. Barrieu et al., 2014; Tang \& Yang, 2012; Jobst, 2014) state that tools for measuring SR have not been developed yet, the universal definition of the SR measure has not yet been established. Oh and Patton (2018) and Reboredo and Ugolini (2015) show that the C-DCC-GARCH model enables the study of SR in the banking sector, considering turbulences on financial markets. In our work, we confirm that the model also works in the insurance sector. The novelty of our article lies in the creation of a model that combines taxonomic methods with the econometric C-CDD-GARCH model. As the basis for our study, we took stock prices of the five largest insurers from Europe and the biggest insurers from the USA, Canada, and China (cf. Table 1 and Figure 1), along with the STOXX 600 Europe Insurance index representing the European insurance market (cf. Figure 2). Data were obtained from the Thomson Reuters in January 2019. We analysed the weekly log returns for the period between January 2005 and December 2018.

Table 1. Insurance companies considered in the study with their acronyms used in the presentation of results

\begin{tabular}{|c|l|c|l|c|}
\hline No. & \multicolumn{1}{|c|}{ Insurer } & Acronym & \multicolumn{1}{c|}{ Country } & Total assets (in bln USD) \\
\hline 1 & AXA & AXA & France & 944.145 \\
\hline 2 & Allianz & Allianz & Germany & 934.654 \\
\hline 3 & Prudential plc & Prud & United Kingdom & 578.149 \\
\hline 4 & Legal \& General & Legal & United Kingdom & 574.901 \\
\hline 5 & Aviva & Aviva & United Kingdom & 541.188 \\
\hline 6 & Metlife & Metlife & USA & 898.764 \\
\hline 7 & Manulife Financial & Manu & Canada & 534.705 \\
\hline 8 & Ping An Insurance & Ping & China & 802.975 \\
\hline
\end{tabular}

Source: own elaboration based on of data from http://www.relbanks.com/top-insurance-companies/world (15 January 2019). 
All insurers besides Legal \& General and Manulife Financial are listed by G-SII according to the principles suggested by the Association of Insurance Supervisors (IAIS) in Basel in 2013, which established how to evaluate financial institutions as far as systemic importance is concerned.

In the first stage of our study, we identified the regimes of insurance market on the basis of the conditional variances of rates of return of the insurance companies under scrutiny. We assessed these conditional variances using the eight-variate C-DCC-GARCH model. During the analysis, we considered various ARMA-GARCH specifications of univariate models. Finally, on the grounds of information criteria and model appropriateness tests (result available upon request to the authors), we opted for all the instruments, i.e. for the $\operatorname{ARMA}(1,1)-\operatorname{eGARCH}(2,2)$ model with the skew Student distribution (with skewness $\xi$ and shape $u$ ); the eGARCH meaning exponential GARCH model put forward by Nelson. During the analysis of the dynamics of dependences between the rates of return, we considered the Gauss and Student copula together with various specifications of the DCC model. As earlier, on the basis of information criteria, we chose the Student copula with conditional correlation coefficients obtained from the $\operatorname{DCC}(1,1)$ model and a constant shape parameter $\eta$. The assessment results are presented in Table 2 , while the conditional variances obtained are shown in Figure 3.
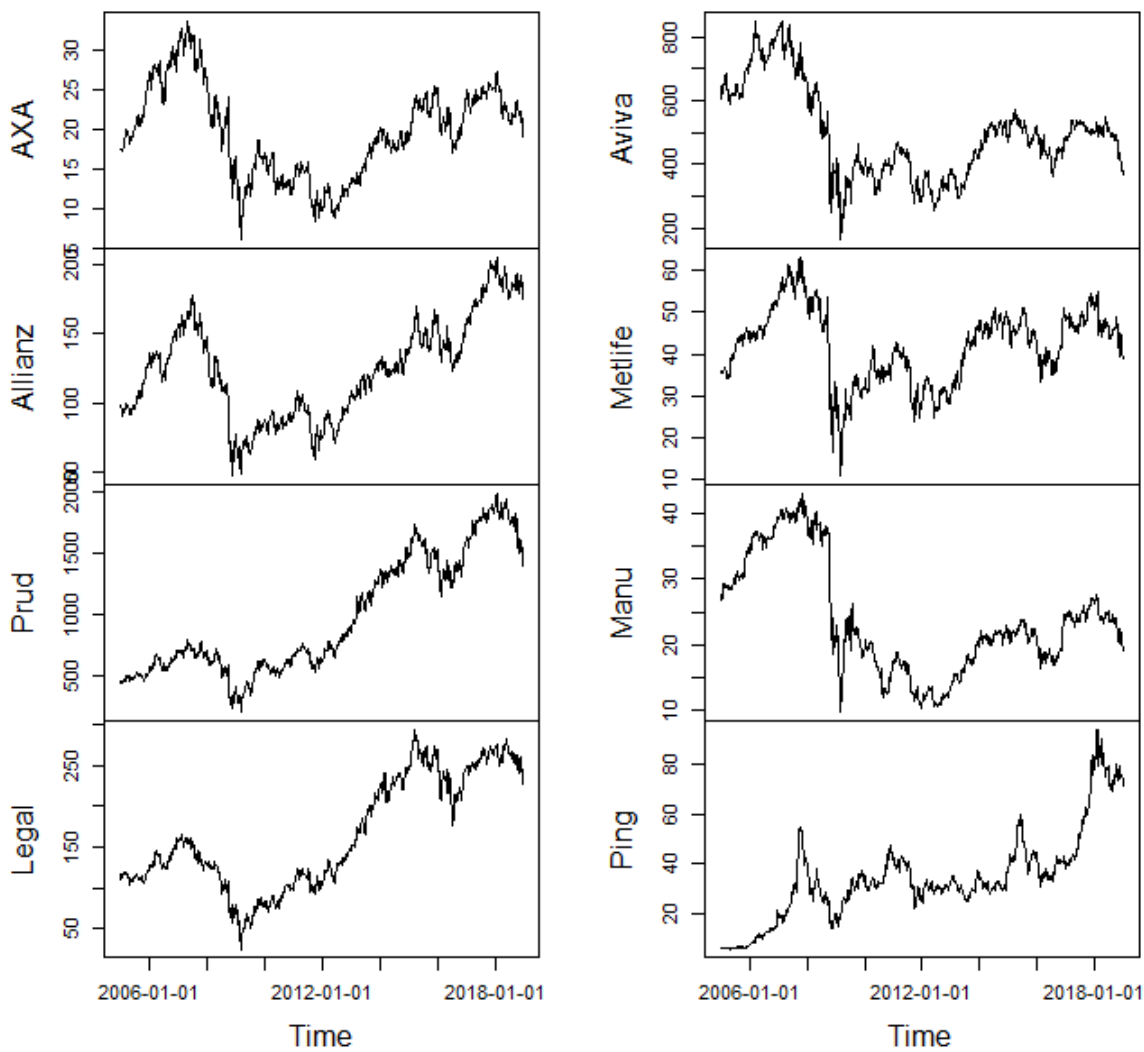

Figure 1. Quotations of insurance companies studied for the period 07.01.2005-21.12.2018 Source: own elaboration. 


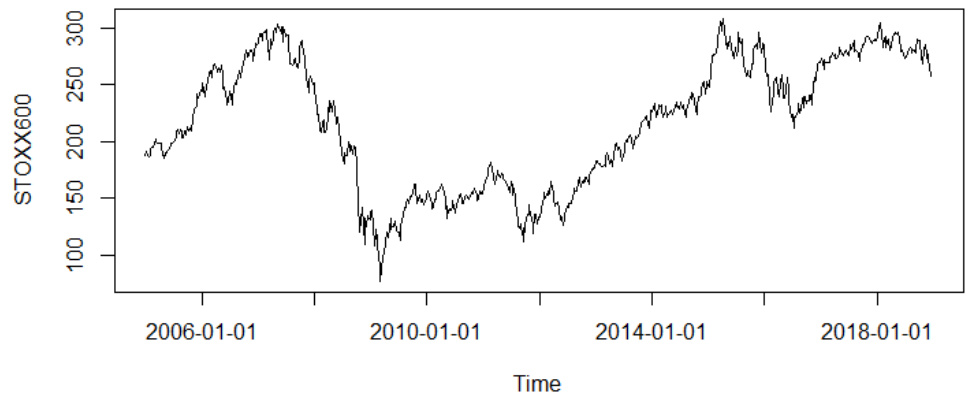

Figure 2. STOXX 600 Europe Insurance index during the period 07.01.2005-21.12.2018 Source: own elaboration.

Table 2. C-DCC-GARCH model estimation results

\begin{tabular}{|c|c|c|c|c|c|c|c|c|}
\hline Param. & AXA & Allianz & Prud & Legal & Aviva & Metlife & Manu & Ping \\
\hline \multirow{2}{*}{$M$} & 0.0010 & 0.0011 & 0.0009 & 0.0011 & -0.0006 & 0.0009 & 0.0003 & 0.0039 \\
\hline & 0.3569 & 0.3294 & 0.2815 & 0.0604 & 0.5609 & 0.0930 & 0.8047 & 0.0198 \\
\hline \multirow{2}{*}{$\varphi_{1}$} & 0.8445 & 0.2844 & 0.6072 & 0.7425 & 0.7211 & 0.7876 & -0.8687 & -0.9367 \\
\hline & 0.0000 & 0.0000 & 0.0000 & 0.0000 & 0.0000 & 0.0000 & 0.0005 & 0.0000 \\
\hline \multirow{2}{*}{$\vartheta_{1}$} & -0.8897 & -0.3397 & -0.7336 & -0.8123 & -0.7797 & -0.8440 & 0.8056 & 0.9118 \\
\hline & 0.0000 & 0.0000 & 0.0000 & 0.0000 & 0.0000 & 0.0000 & 0.0073 & 0.0000 \\
\hline \multirow{2}{*}{$\Omega$} & -0.1891 & -0.2024 & -0.1287 & -0.1854 & -0.2492 & -0.1608 & -0.2018 & -0.2718 \\
\hline & 0.0000 & 0.0001 & 0.0011 & 0.0282 & 0.0040 & 0.0041 & 0.0123 & 0.0848 \\
\hline \multirow[b]{2}{*}{$\alpha_{1}$} & -0.3000 & -0.2597 & -0.1974 & -0.2058 & -0.1721 & -0.1963 & -0.1868 & -0.0396 \\
\hline & 0.0000 & 0.0000 & 0.0003 & 0.0191 & 0.0003 & 0.0000 & 0.0097 & 0.3617 \\
\hline \multirow{2}{*}{$\alpha_{2}$} & 0.2021 & 0.1564 & 0.0907 & 0.1036 & -0.0184 & 0.0810 & 0.0225 & 0.0356 \\
\hline & 0.0002 & 0.0125 & 0.1053 & 0.3209 & 0.7349 & 0.0084 & 0.7240 & 0.4804 \\
\hline \multirow{2}{*}{$B_{1}$} & 1.0000 & 1.0000 & 1.0000 & 1.0000 & 0.1931 & 1.0000 & 0.5951 & 0.2430 \\
\hline & 0.0000 & 0.0000 & 0.0000 & 0.0000 & 0.0000 & 0.0000 & 0.0000 & 0.0000 \\
\hline \multirow{2}{*}{$B_{2}$} & -0.0299 & -0.0300 & -0.0205 & -0.0284 & 0.7682 & -0.0252 & 0.3751 & 0.7113 \\
\hline & 0.0000 & 0.0001 & 0.0009 & 0.0376 & 0.0000 & 0.0044 & 0.0000 & 0.0000 \\
\hline \multirow{2}{*}{$\gamma_{1}$} & -0.0366 & 0.0532 & -0.0929 & 0.1295 & 0.0277 & 0.1169 & 0.1414 & 0.2838 \\
\hline & 0.6340 & 0.6021 & 0.2804 & 0.2064 & 0.7292 & 0.2584 & 0.1533 & 0.0000 \\
\hline \multirow[b]{2}{*}{$V_{2}$} & 0.1790 & 0.0507 & 0.2159 & 0.0764 & 0.3062 & 0.0103 & 0.0824 & 0.0932 \\
\hline & 0.0334 & 0.6303 & 0.0186 & 0.4639 & 0.0001 & 0.9199 & 0.3380 & 0.2080 \\
\hline \multirow{2}{*}{$\begin{array}{c}\xi \\
\text { (skew.) }\end{array}$} & 0.8519 & 0.8332 & 0.8022 & 0.8906 & 0.8152 & 0.8709 & 0.9219 & 1.1321 \\
\hline & 0.0000 & 0.0000 & 0.0000 & 0.0000 & 0.0000 & 0.0000 & 0.0000 & 0.0000 \\
\hline \multirow{2}{*}{$\begin{array}{c}u \\
\text { (shape) }\end{array}$} & 11.7322 & 10.1324 & 6.0408 & 5.4374 & 6.0600 & $\begin{array}{ll}4.5168 \\
\end{array}$ & 5.0649 & 5.4819 \\
\hline & 0.0118 & 0.0079 & 0.0000 & 0.0000 & 0.0000 & 0.0000 & 0.0000 & 0.0000 \\
\hline \multicolumn{9}{|c|}{ C-DCC parameters } \\
\hline \multicolumn{2}{|c|}{ Distribution } & \multicolumn{7}{|c|}{ Octovariate t-Student } \\
\hline \multirow{2}{*}{\multicolumn{2}{|c|}{ DCC order }} & \multicolumn{7}{|c|}{$\operatorname{DCC}(1,1)$} \\
\hline & & \multicolumn{7}{|c|}{ Parameters } \\
\hline \multicolumn{2}{|c|}{$c_{1}$} & \multicolumn{7}{|c|}{$0.01063(0.00012)$} \\
\hline \multicolumn{2}{|c|}{$d_{1}$} & \multicolumn{7}{|c|}{$0.94801(0.00000)$} \\
\hline \multicolumn{2}{|c|}{$\eta$ (shape) } & \multicolumn{7}{|c|}{$9.96436(0.00000)$} \\
\hline
\end{tabular}

The numbers in parentheses are probability values ( $p$-values).

Source: own study. 
Market regimes were identified by means of clustering weekly periods with respect to the conditional variances in insurance companies' rates of return. In this crucial step - from the viewpoint of the whole study - we considered various combinations of distance measures, clustering methods, and a number of classes. Eventually, following criteria of clustering quality (cf. Table 3), we chose a division into two classes obtained using the method of k-means with the Euclidean distance (cf. Figure 4). In this case, the silhouette index is 0.8683 (clustering quality is pictured in Figure 5). We assumed that different market regimes correspond to different classes. The variance distribution in different regimes is shown in Figure 6. We can infer from Figure 6 that the first regime is characterised by low volatility (low risk level), while the second one - occurring during the period 17.10.2008-05.06.2009 - by high volatility (high risk level).

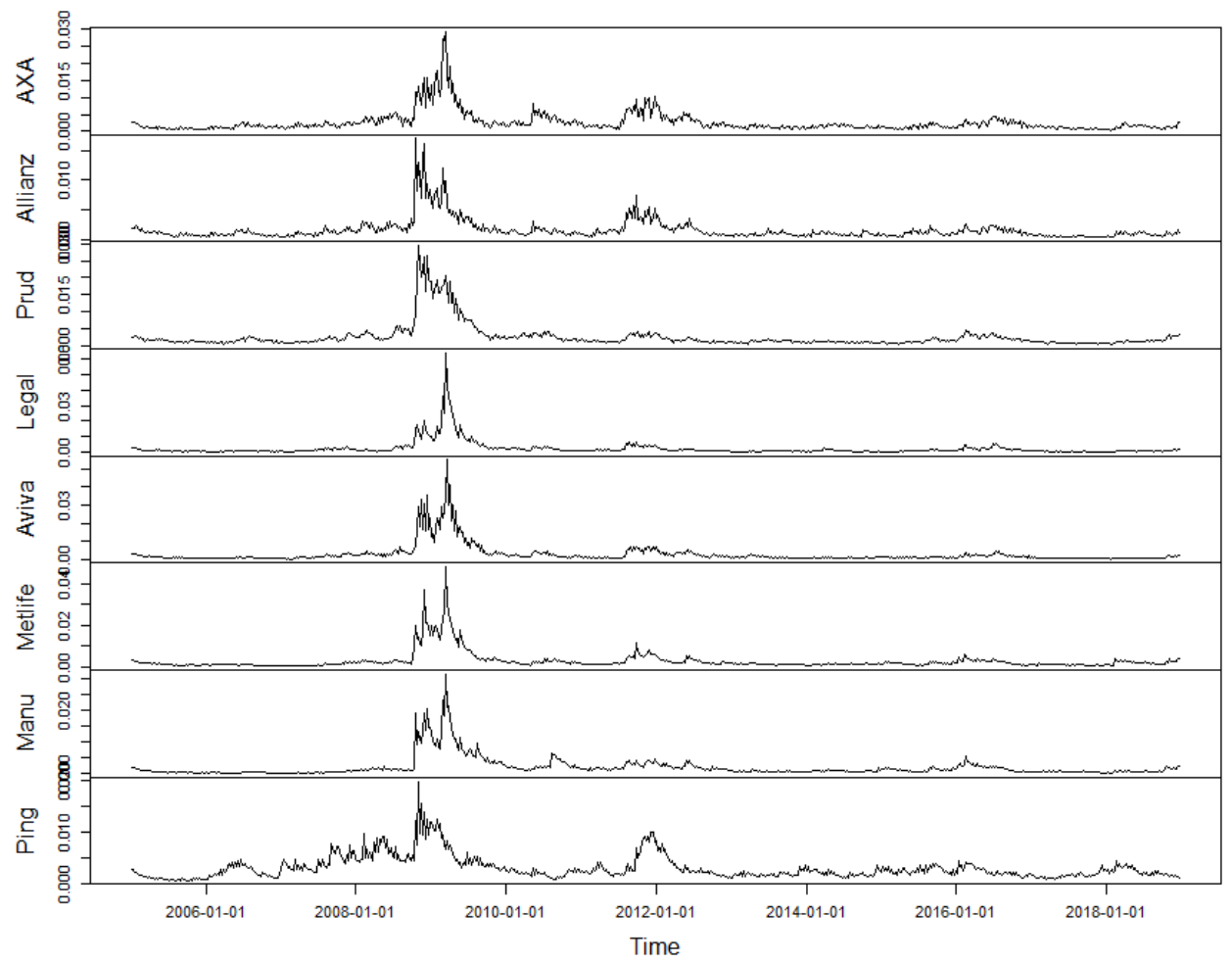

Figure 3. Conditional variances

Source: own elaboration.

In the second step of our study, we analysed dependences between the studied insurance companies based on the conditional correlations from the previously assessed octovariate c-DCC-GARCH model. Their distribution for the respective pairs in the identified market regimes is shown in Figure 7.

On the other hand, the analysis of dependences between the insurer and the European insurance market - but also the analysis of systemic risk in the first and second market regime - was conducted on the basis of the estimated eight-bivariate C-DCC-GARCH 
models for the following pairs: the rate of return on the European market index and the individual rate of return for a given insurance company. The models were evaluated on the basis of the whole history of occurrences. In the case of insurers, we employed the earlier estimated $\operatorname{ARMA}(1,1)-\operatorname{eGARCH}(2,2)$ models with the skew Student distribution.

On the grounds of information criteria and model appropriateness tests, we considered the same specification for the STOXX 600 Europe Insurance index rate of return. The parameters of the estimated model are given in Table 4 . During the analysis of the

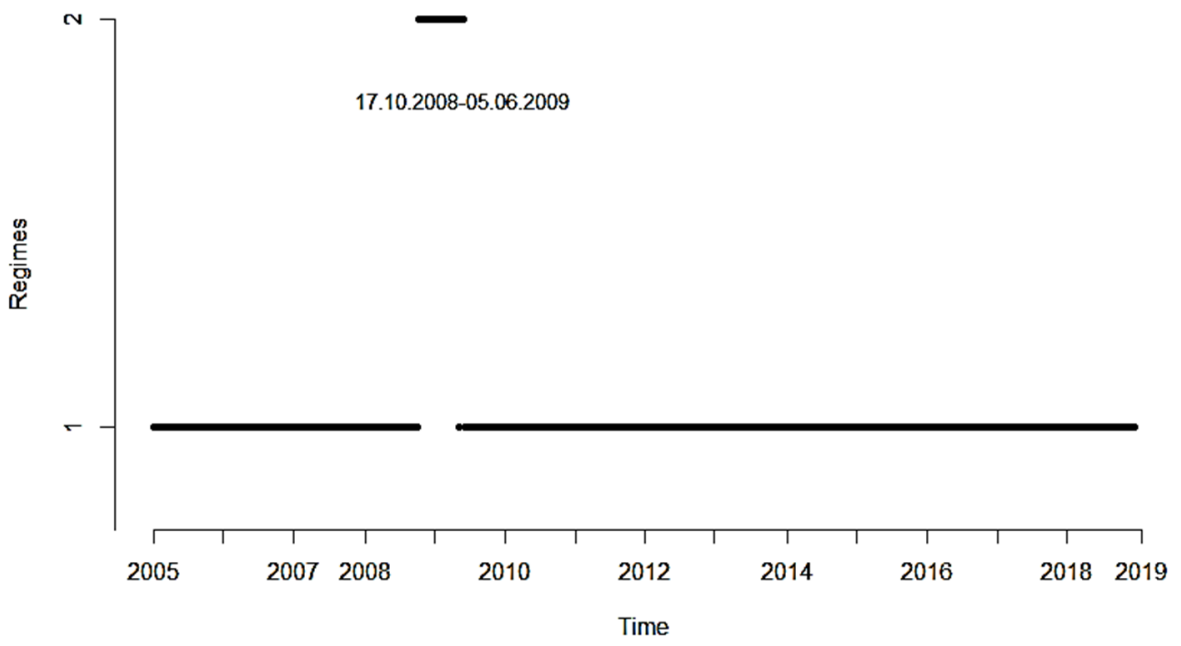

Figure 4. Identified market regimes

Source: own elaboration.

Table 3. Validation indices for data partitions

\begin{tabular}{|l|r|r|r|r|r|}
\hline \multirow{2}{*}{ Validation criterion } & \multicolumn{5}{|c|}{ Number of clusters } \\
\cline { 2 - 6 } & \multicolumn{1}{|c|}{$\mathbf{2}$} & $\mathbf{3}$ & \multicolumn{1}{c|}{$\mathbf{4}$} & \multicolumn{1}{c|}{$\mathbf{5}$} & \multicolumn{1}{c|}{$\mathbf{6}$} \\
\hline & \multicolumn{5}{|c|}{ Ward's meth od } \\
\hline Silhouette & $\mathbf{0 . 8 6 8 3}$ & 0.4202 & 0.3958 & 0.3987 & 0.3986 \\
\hline Calinski Harabasz index & $\mathbf{1 5 4 5 . 1 5 7 0}$ & 1006.8530 & 771.5901 & 963.3596 & 814.7552 \\
\hline Dunn index & $\mathbf{0 . 0 5 5 2}$ & 0.0080 & 0.0080 & 0.0110 & 0.0110 \\
\hline Xie-Beni index & $\mathbf{1 . 9 2 0 8}$ & 76.1650 & 68.5520 & 45.4610 & 43.3223 \\
\hline & \multicolumn{5}{|c|}{ PAM } \\
\hline Silhouette & $\mathbf{0 . 8 6 2 3}$ & 0.4788 & 0.4153 & 0.4181 & 0.1549 \\
\hline Calinski Harabasz index & $\mathbf{1 5 0 1 . 2 9 5 0}$ & 1036.3830 & 791.2769 & 990.6590 & 809.8822 \\
\hline Dunn index & $\mathbf{0 . 0 3 5 3}$ & 0.0082 & 0.0077 & 0.0104 & 0.0053 \\
\hline Xie-Beni index & $\mathbf{4 . 1 4 4 4}$ & 66.2503 & 72.2987 & 47.7384 & 177.4645 \\
\hline & \multicolumn{5}{|c|}{ k-m ea n s } \\
\hline Silhouette & $\mathbf{0 . 8 6 8 3}$ & 0.5238 & 0.5177 & 0.4713 & 0.4394 \\
\hline Calinski Harabasz index & $\mathbf{1 5 4 5 . 1 5 7 0}$ & 1063.6570 & 1170.1440 & 1047.2740 & 915.3568 \\
\hline Dunn index & $\mathbf{0 . 0 5 5 2}$ & 0.0071 & 0.0106 & 0.0146 & 0.0127 \\
\hline Xie-Beni index & $\mathbf{1 . 9 2 0 8}$ & 92.8171 & 62.4426 & 28.7042 & 34.8416 \\
\hline
\end{tabular}

Note: numbers in bold indicate the optimal number of groups with reference to a given criterion.

Source: own study. 


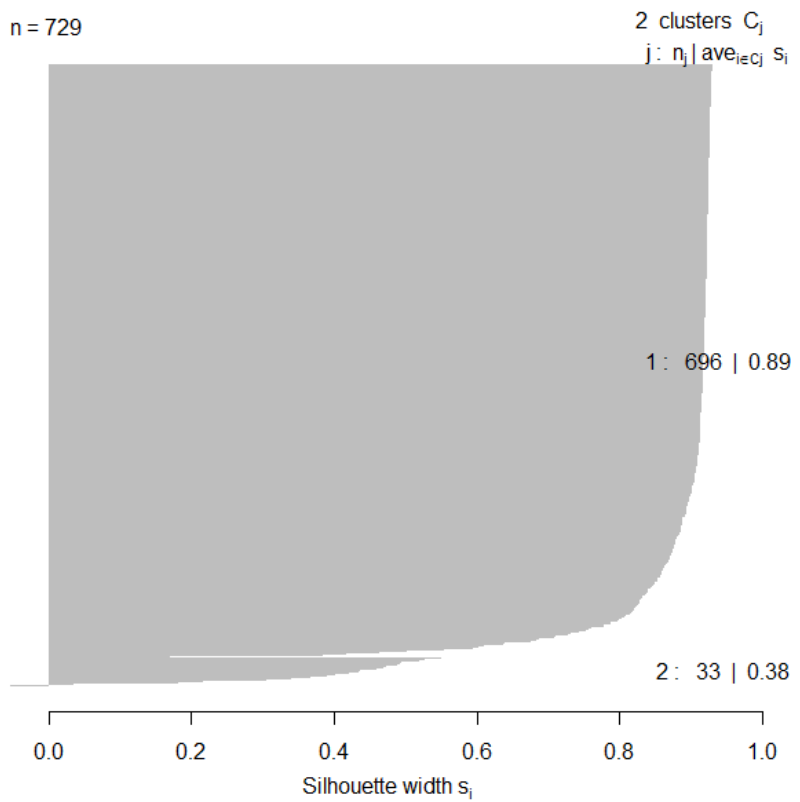

Average silhouette width : 0.87

Figure 5. Silhouette plot

Source: own elaboration.

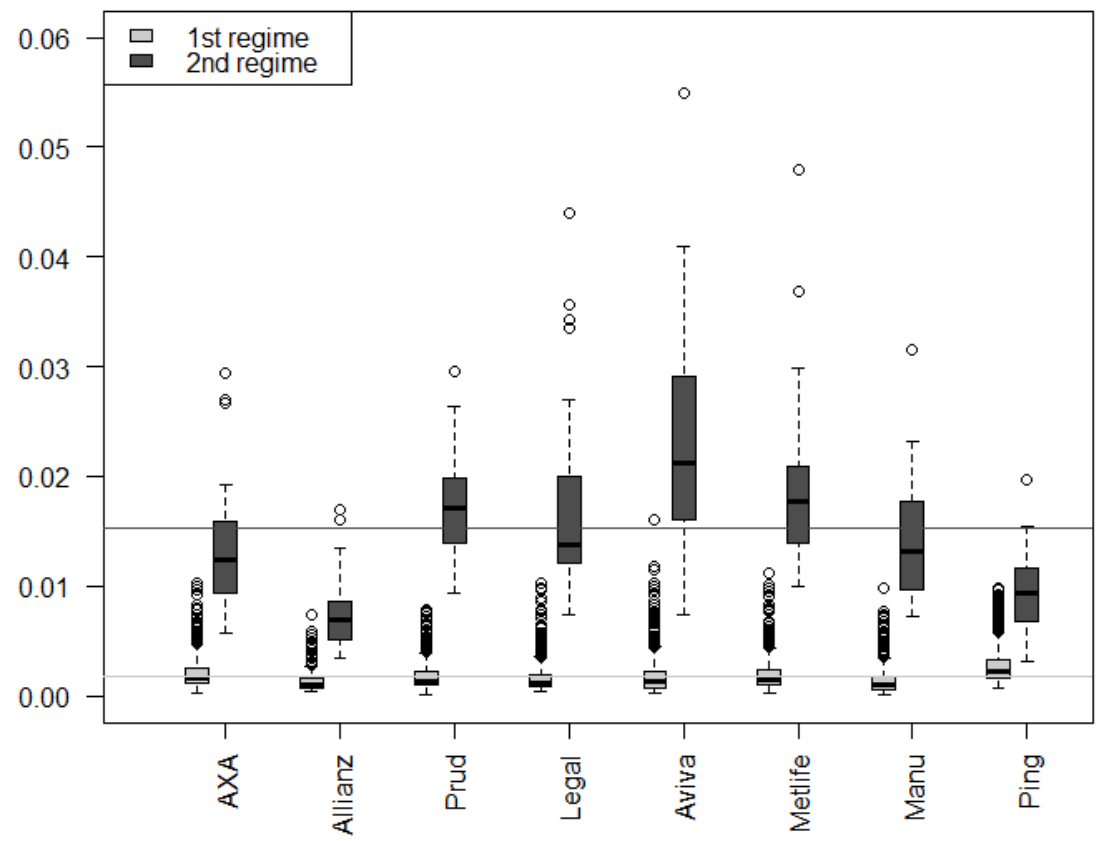

Figure 6. Boxplots for the conditional variance in the identified market regimes Source: own elaboration. 
dynamics between the rate of return on the index representing the European insurance market and the insurers' rates of return, we considered the Gauss and Student copulae, along with various specifications of the DCC model. On the basis of information criteria for each pair, we chose the Student copula with conditional correlations obtained from the $\operatorname{DCC}(1,1)$ model and constant shape parameters. The estimation results are presented in Table 5, while the conditional correlations obtained are shown in Figure 8. Finally, the distribution of the conditional correlations between the domestic and European capital markets in the identified regimes is given in Figure 9.

Systemic risk assessment in identified market regimes was performed using the CoVaR measure determined by the method described in the previous section. The Co$V a R$ value distribution illustrating the influence of a given insurer on the European insurance market is shown in Figure 10.

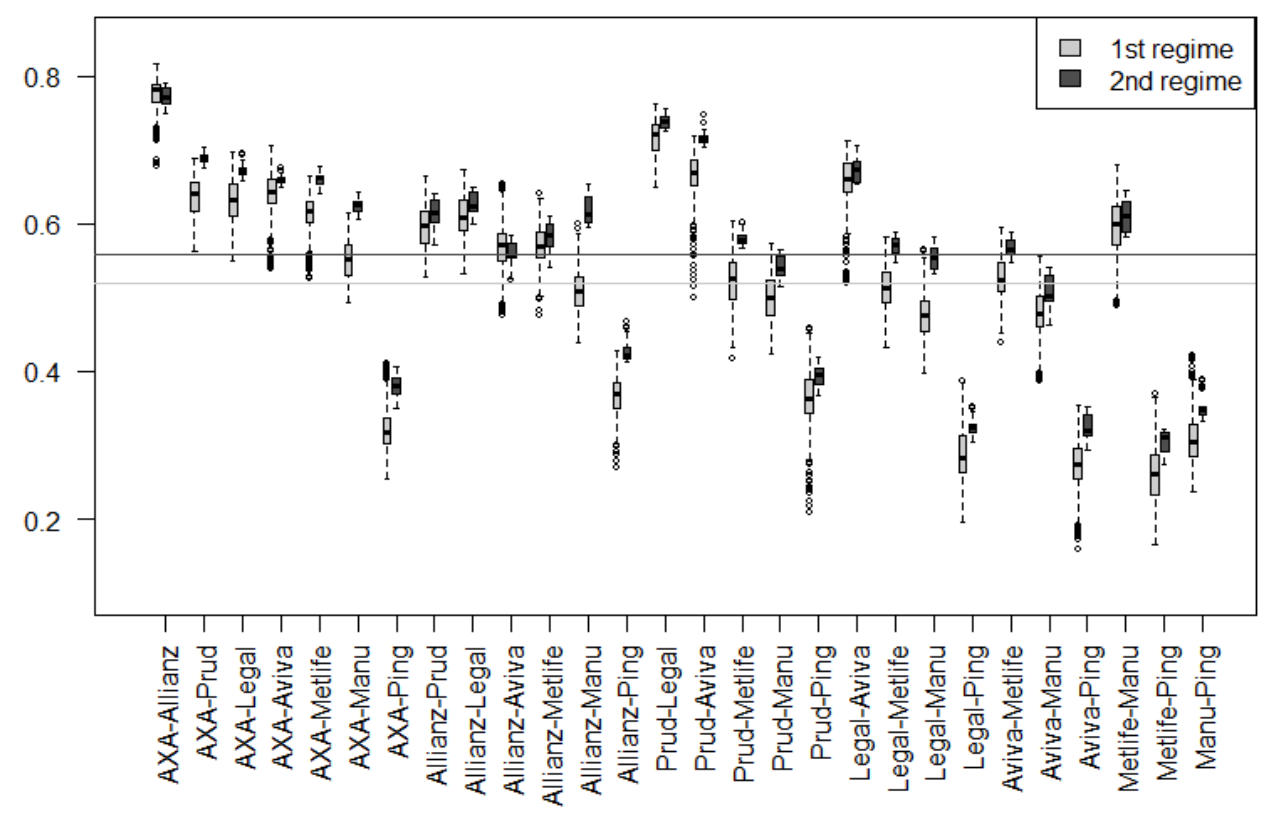

Figure 7. Boxplots for the conditional correlations between analysed markets in the identified regimes

Source: own elaboration.

Market regimes were established to check whether the systemic importance of the surveyed largest insurers from Europe, North America, and Asia is at a similar level during the normal period and during the turbulence in the insurance markets. Such information is important for decision-makers who shape the macro-prudential policy of the European insurance sector; in particular regarding the method of determining insurers of global systemic importance. From the studies conducted upon the eight insurers, a hypothesis follows that the level of SR generation increases in the second state in the period from October 17, 2008 to June 5, 2009 shown in Figure 7. A significantly higher level of SR in the state of turbulence means that during turmoil on financial markets, the strength of the negative impact of individual insurance units upon the whole insurance sector increases. 
Table 4. Univariate ARMA(1, 1)- $\operatorname{eGARCH}(2,2)$ model estimations for the STOXX 600 Europe Insurance index

\begin{tabular}{|l|c|c|c|c|c|c|}
\hline \multicolumn{1}{|c|}{ Parameter } & $\boldsymbol{M}$ & $\boldsymbol{\varphi}_{\mathbf{1}}$ & $\boldsymbol{\vartheta}_{\mathbf{1}}$ & $\boldsymbol{\Omega}$ & $\boldsymbol{\alpha}_{\mathbf{1}}$ & $\boldsymbol{\alpha}_{\mathbf{2}}$ \\
\hline estimation & 0.00086 & 0.68392 & -0.72741 & -0.20234 & -0.25814 & 0.16812 \\
p-Value & 0.35844 & 0.00000 & 0.00000 & 0.00221 & 0.00003 & 0.00570 \\
\hline \multicolumn{1}{|l|}{ Parameter } & $\boldsymbol{B}_{\mathbf{1}}$ & $\boldsymbol{B}_{\mathbf{2}}$ & $\boldsymbol{V}_{\mathbf{1}}$ & $\boldsymbol{V}_{\mathbf{2}}$ & $\boldsymbol{\xi}$ (skew.) & $\boldsymbol{u}$ (shape) \\
\hline estimation & 1.00000 & -0.02848 & 0.09708 & 0.05358 & 0.79261 & 9.87665 \\
p-Value & 0.00000 & 0.00691 & 0.35870 & 0.60707 & 0.00000 & 0.00438 \\
\hline
\end{tabular}

Source: own study.

Table 5. Bivariate $\operatorname{DCC}(1,1)$ models estimations for the pairs: STOXX 600 Europe Insurance and a given insurer

\begin{tabular}{|c|c|r|r|r|r|r|r|r|}
\hline Indicator & \multicolumn{1}{|c|}{ AXA } & Allianz & Prud & \multicolumn{1}{c|}{ Legal } & Aviva & Metlife & Manu & \multicolumn{1}{c|}{ Ping } \\
\hline \multirow{2}{*}{$c_{1}$} & 0.02513 & 0.02159 & 0.03199 & 0.04218 & 0.02631 & 0.07105 & 0.03338 & 0.00942 \\
\cline { 2 - 9 } & 0.04014 & 0.01083 & 0.02421 & 0.00990 & 0.00191 & 0.02998 & 0.08039 & 0.73776 \\
\hline \multirow{2}{*}{$d_{1}$} & 0.95214 & 0.96262 & 0.94015 & 0.92320 & 0.96805 & 0.72663 & 0.90777 & 0.85545 \\
\cline { 2 - 9 } & 0.00000 & 0.00000 & 0.00000 & 0.00000 & 0.00000 & 0.00027 & 0.00000 & 0.32845 \\
\hline \multirow{2}{*}{$\eta$ (shape) } & 6.85867 & 11.11860 & 8.13343 & 7.99758 & 6.31898 & 16.80825 & 7.86310 & 15.97758 \\
\cline { 2 - 8 } & 0.00026 & 0.00241 & 0.00000 & 0.00012 & 0.00000 & 0.10873 & 0.00122 & 0.14136 \\
\hline
\end{tabular}

Source: own study.

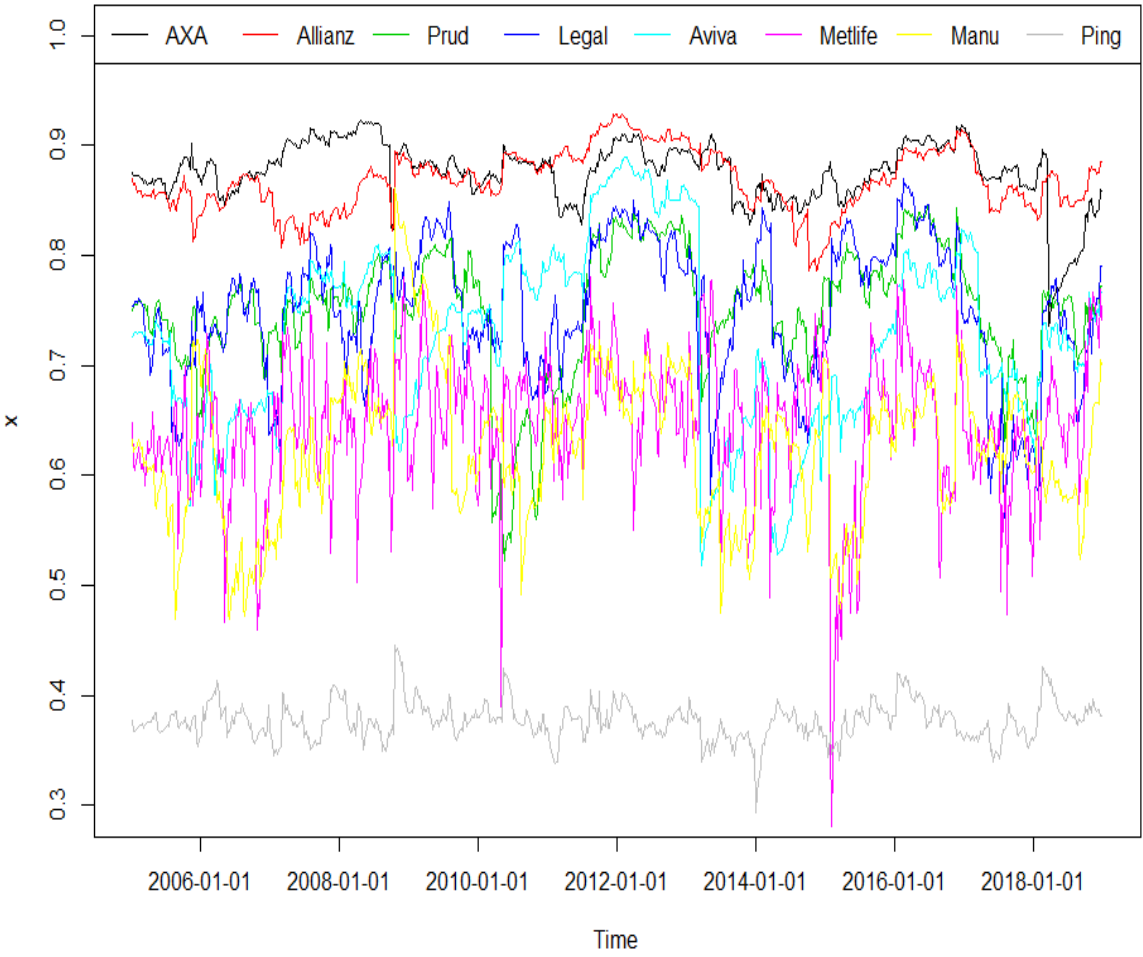

Figure 8. Conditional correlations between the insurer and the European insurance market Source: own elaboration. 


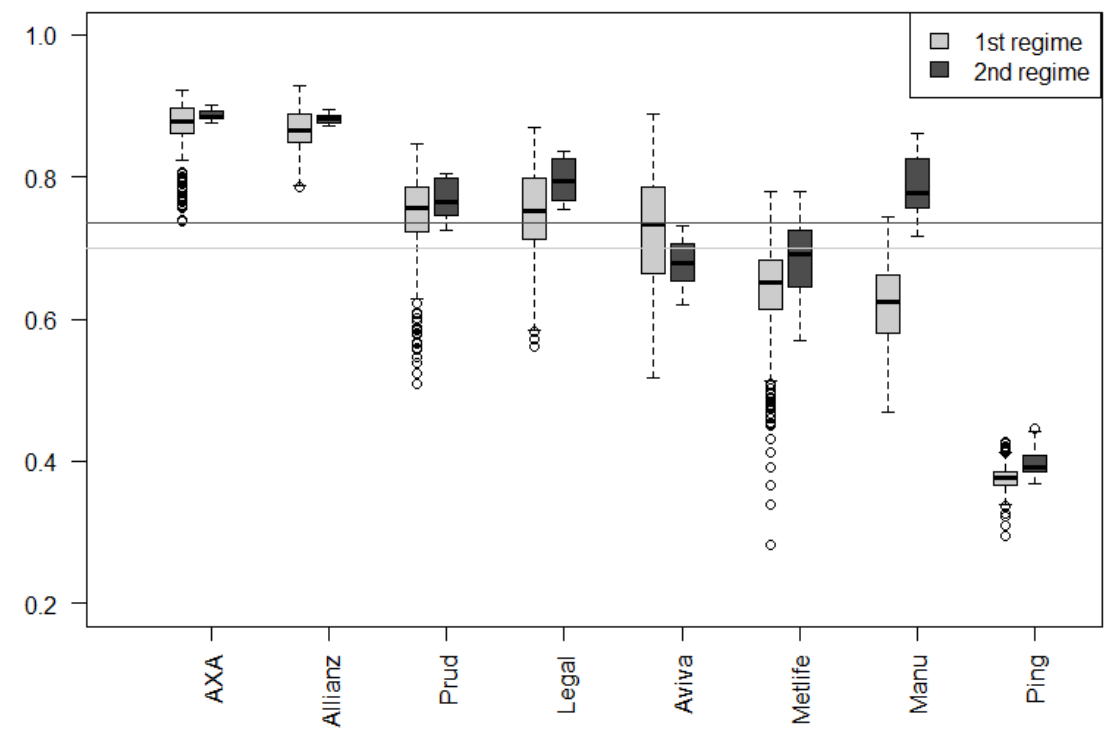

Figure 9. Boxplots for the conditional correlations between the insurer and the European insurance market in the identified regimes Source: own elaboration.

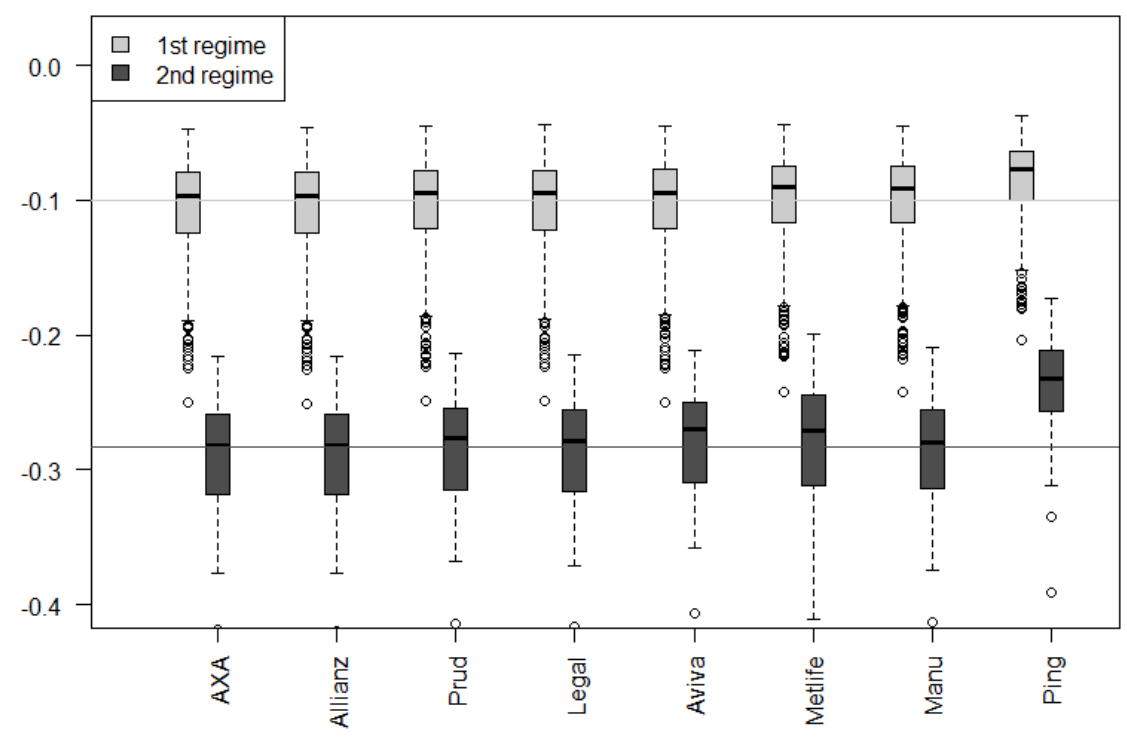

Figure 10. Boxplots for the CoVaR measure in the identified regimes Source: own elaboration.

Market regimes were established to check whether the systemic importance of the surveyed largest insurers from Europe, North America, and Asia is at a similar level during the normal period and during the turbulence in the insurance markets. Such information 
is important for decision-makers who shape the macro-prudential policy of the European insurance sector; in particular regarding the method of determining insurers of global systemic importance. From the studies conducted upon the eight insurers, a hypothesis follows that the level of SR generation increases in the second state in the period from October 17, 2008 to June 5, 2009 shown in Figure 7. A significantly higher level of SR in the state of turbulence means that during turmoil on financial markets, the strength of the negative impact of individual insurance units upon the whole insurance sector increases.

\section{CONCLUSIONS}

In this article, we used the C-DCC-GARCH model to analyse dependences in a group formed by the largest five insurance companies from Europe and the biggest insurers from the USA, Canada, and China. Then, availing ourselves of the CoVaR measure, we studied the influence of each insurer on the European insurance market systemic risk. The European market was represented by the STOXX 600 Europe Insurance index, while for the insurers, we considered their quotations on domestic markets. The study was performed in two steps. The first one consisted in identifying regimes of European insurance market, while the second one analysed the following items for the identified regimes: correlations among the scrutinised insurance companies (using conditional correlations), dependences between a given insurer and the European insurance market, and the influence of analysed insurance companies on the European insurance market systemic risk. The market regimes were identified by monitoring the insurers' logarithmic returns on shares. To this end, we applied statistical clustering methods for weekly periods to which we assigned the conditional variances obtained from the estimated octovariate c-DCC-GARCH model. Both the clustering quality measures and the possibility of a reasonable economic interpretation exposed two different market regimes in the considered period of time: a regime of low volatility (1st regime, 'normal') and a regime of unstable quotations ( 2 nd regime, 'risky'), which appeared during the time of the strongest turbulences experienced by the global markets.

We may draw the following conclusions from our study:

- The insurance companies from the investigated group are positively correlated. The strongest dependence appears among insurers from Europe - Axa and Allianz are a pair with the strongest tie - a somewhat weaker dependence exists between insurers from Europe and those from North America, while the weakest link shows between the insurer from China and the others. These correlations are clearly stronger in the second identified regime, i.e. during the period of turbulences on global markets (cf. Figure 7). On that basis, we may state that during a global crisis, the exposure to systemic risk on the European insurance market increases, because the stronger the link between insurance companies, the greater the likelihood of the spread of negative effects of financial shocks.

- The European insurance market - as represented by the STOXX 600 Europe Insurance index - is most strongly correlated to the largest insurance companies from Europe, i.e. Axa or Allianz. A weaker correlation exists in the case of insurers from North America and a notably weaker still in the case of the insurer from China (cf. Figure 8). As earlier, these correlations are stronger in the second market regime (cf. Figure 9). Noteworthy, these results may be biased to some extent by the construction of the STOXX 600 Europe Insurance index. 
- There is an important difference between the CoVaR measures for the first and second regimes of the European insurance market in the case of all the insurers from the studied group. The influence of insurance companies on systemic risk is much stronger during turbulences periods (cf. Figure 10). It is also apparent that in a fixed regime this influence remains more or less at the same level, which in the case of the insurer from China is somewhat lower than average.

- The influence of North American insurance companies on the European insurance market's systemic risk is at a comparative level with the influence of companies from Europe, both in the first and second identified market regimes.

The world entered the twenty-first century, the era of digital economy and the so-called Fourth Industrial Revolution. According to the G20 report, digital economy is defined by economic activity in which digitised information and knowledge are considered to be key production factors, together with the development of a modern information network that accelerates growth and optimises economic structures. The International Monetary Fund (IMF) broadly defines digital economy as digitization in all sectors of the economy.

In the digital age of Fintech, the combination of finance and technology plays an increasingly important role. The financial supervisory and macro-prudential authorities for Systemically Important Financial Institutions (SIFI) now face new challenges, while the prevention of SR is one of the most important elements of globalised policy and economics. Since the reports of the Financial Stability Board (FSB), International Association of Insurance Supervisors (IAIS), and the European Systemic Risk Board (ESRB) keep indicating the lack of tools to describe and measure SR in the insurance sector, further research should concentrate on the search for SR measure. Moreover, scholars should focus on determining the mathematical, statistical, and econometric tools in order to build models that would allow the prediction of adverse phenomena on the insurance market.

The present article uses statistical-econometric tools, a combination of taxonomic methods with the C-DCC-GARCH model, to utilise them in a more widely planned research on SR in the insurance sector when constructing hybrid models using e.g. network theory, as in Denkowska and Wanat (2020).

The article presents several new results, yet it also has some limitations that can be improved in further studies. Based on the presented results in the form of boxplots, we noticed that the overall correlation between companies is higher during turbulence periods. Stronger connections make the whole system more vulnerable to systemic risk, hence the conclusion about the increase in exposure to this risk. However, we did not investigate whether average correlations were significantly different in distinguished states. Nevertheless, this thread of analysis can inspire future studies in which the significance of network connections for systemic risk in the insurance sector is analysed using Minimum Spanning Trees.

\section{REFERENCES}

Acharya, V.V., Pedersen, L.H., Philippon, T., \& Richardson, M.P. (2010). Measuring Systemic Risk, SSRN Electronic Journal. https://doi.org/10.2139/ssrn.1573171

Baluch, F., Mutenga, S., \& Parsons, C. (2011). Insurance, Systemic Risk and the Financial Crisis. The Geneva Papers on Risk and Insurance - Issues and Practice, 36(1), 126-163. https://doi.org 10.1057/gpp.2010.40. 
Barrieu, P., \& Scandolo, G. (2014). Assessing financial model risk. European Journal of Operational Research, 1-30.

Baur, P., Enz, R., \& Zanetti, A. (2003). Reinsurance-A Systemic Risk?. Zürich: Swiss.

Bell, M., \& Keller, B. (2009). Insurance and Stability: The Reform of Insurance Regulation (Zurich Financial Services Group Working Paper). Zurich, Switzerland Bernanke.

Berdin, E., \& Sottocornola, M. (2015). Assessing Systemic Risk of the European Insurance Industry. Financial Stability Report, EIOPA, 57-75.

Bernal, O., Gnabo, J.-Y., \& Guilmin, G. (2014). Assessing the contribution of banks, insurance and other financial services to systemic risk. Journal of Banking \& Finance, 47, 270-287.

Bernardi, M., \& Catania, L. (2015). Switching GAS Copula Models for Systemic Risk Assessment.arXiv:1504.03733v1 [stat.ME]

Bierth, C., Irresberger, F., \& Weiß, G.N.F. (2015). Systemic risk of insurers around the globe. Journal of Banking \& Finance, 55, 232-245. https://doi.org/ 10.1016/j.jbankfin.2015.02.014

Billio, M., Getmansky, M., Lo, A.W., \& Pelizzon, L. (2012). Econometric measures of connectedness and systemic risk in the finance and insurance sectors. Journal of Financial Economics, 104(3), 535-559. https://doi.org/10.1016/j.jfineco.2011.12.010

Box, G.E.P., \& Jenkins, G.M. (1970). Time Series Analysis: Forecasting and Control. San Francisco: Holden-Day.

Brechmann, C., Hendrich, K., \& Czado, C. (2013). Conditional copula simulation for systemic risk stress testing. Insurance: Mathematics and Economics,53(3), 722-732.

Calinski, T., \& Harabasz, J. (1974). A dendrite method for cluster analysis. Communications in Statistics, 3(1), 1-27.

Chen, H., Cummins, J.D., Viswanathan, K.S., \& Weiss, M.A. (2013). Systemic Risk and the Interconnectedness Between Banks and Insurers: An Econometric Analysis. Journal of Risk and Insurance, 81(3), 623-652. https://doi.org/10.1111/j.1539-6975.2012.01503.x

Cummins, J.D., \& Weiss, M.A. (2014a; 2014b). Systemic Risk and The U.S. Insurance Sector. Journal of Risk and Insurance, 81(3), 489-527. https://doi.org//10.1111/jori.12039

Czerwińska, T. (2014). Systemic risk in the insurance sector, Problemy Zarzadzania, 12(48), 41-63.

Denkowska, A., \& Wanat, S. (2020). A Tail Dependence-Based MST and Their Topological Indicators in Modeling Systemic Risk in the European Insurance Sector. Risks, 8(2), 1-22.

Di Bernardino, E., Fernández-Ponce, J.M., Palacios-Rodríguez, F., \& Rodríguez-Griñolo, M.R. (2015). On multivariate extensions of the conditional Value-at-Risk measure. Insurance: Mathematics and Economics, 61, 1-16.

Di Clemente, A. (2018). Estimating the marginal contribution to systemic risk by a CoVar-model based on copula functions and extreme value theory. Economic Notes by Banca Monte dei Paschi di Siena SpA, 47(1), 69-112.

Dungey, M., Luciani, M., \& Veredas, D. (2014). The Emergence of Systemically Important Insurers. CIFR paper, 038, September.

Dunn, C.J. (1974) Well-separated clusters and optimal fuzzy partitions. Journal of Cybernetics, 4, 95-104.

EIOPA (2017). Systemic risk and macroprudential policy in insurance. Luxembourg: Publication Office of the European Union.

Eling, M., \& Pankoke, D. (2014). Systemic risk in the insurance sector - what do we know. Working Papers on management and risk insurance, University of St Gallen. 
Engle, R.F. (2002). Dynamic Conditional Correlation: A Simple Class of Multivariate Generalized Autoregressive Conditional Heteroskedasticity Models. Journal of Business and Economic Statistics, 20(3), 339-350. https://doi.org/10.1198/073500102288618487

European Systemic Risk Board. (2015, December). Report on systemic risks in the EU insurance sector.

Fiszeder, P. (2009). Modele klasy GARCH w empirycznych badaniach finansowych. Toruń: Wydawnictwo Naukowe Uniwersytetu Mikołaja Kopernika.

Gajzler, M. (2019). Wykorzystanie bazującego na kopuli modelu delta CoVaR do analizy ryzyka systemowego na europejskim rynku ubezpieczeń. In A. Prędki (Ed.), Zastosowania narzędzi analitycznych w ekonomii, finansach i zarzqdzaniu (pp. 119-129). Kraków: Uniwersytet Ekonomiczny w Krakowie.

Geneva Association. (2010). Systemic risk in insurance: an analysis of insurance and financial stability. Technical report, Special Report of The Geneva Association Systemic Risk Working Group, Switzerland.

Ghalanos, A. (2019). Multivariate GARCH Models. Package 'rmgarch'. CRAN Packages Retrieved from https://cran.r-project.org/web/packages/rmgarch/index.html on January 2020.

Grace, M.F. (2011). The Insurance Industry and Systemic Risk: Evidence and Discussion.Working Paper, Georgia State University.

Harrington, S.E. (2009). The Financial Crisis, Systemic Risk, and the Future of Insurance Regulation. Journal of Risk and Insurance, 76(4), 785-819. https://doi.org/10.1111/j.1539-6975.2009.01330

Hair, J. (1997). Multivariate models and dependence concepts. London: Chapman-Hall.

IAIS. (2011). Insurance and financial stability.

Jobst, A.A. (2014). Systemic Risk in the Insurance Sector: A Review of Current Assessment Approaches.The Geneva Papers on Risk and Insurance - Issues and Practice, 39(3), 440-470. https://doi.org/10.1057/gpp.2013.7

Kanno, M. (2016). The network structure and systemic risk in the global non-life insurance market. Insurance: Mathematics and Economics, 67, 38-53.

Karimalis, E.N., \& Nomikos, N.K. (2018). Measuring systemic risk in the European banking sector: a copula CoVar approach. The European Journal of Finance, 24(11), 944-975.

Kaufman, L., \& Rousseeuw, P.J. (1990). Finding Groups in Data: An Introduction to Cluster Analysis. New York: Wiley \&Sons.

Kessler, D. (2013). Why (Re)insurance is Not Systemic. Journal of Risk and Insurance, 81, (3), 477-488.

van Lelyveld, I., Liedorp, F., \& Kampman, M. (2011). An Empirical Assessment of Reinsurance Risk. Journal of Financial Stability, 7(4), 191-203.

Mühlnickel J., \& Weiß, G.N.F. (2014). Why do some insurers become systemically relevant?.Journal of Financial Stability, 13, 95-117.

Mühlnickel, J., \& Weiß, G.N.F. (2015). Consolidation and systemic risk in the international insurance industry. Journal of Financial Stability 18, 187-202.

Nelson, D.B. (1991). Conditional Heteroskedasticity in Asset Returns: A New Approach. Econometrica, 59, 347-370.

Oh, D.H., \& Patton, A.J. (2018). Time-varying systemic risk: evidence from a dynamic copula model of CDS spreads. Journal of Business and Economic Statistics, 36(2), 181-195.

Patton, A.J. (2006). Modelling asymmetric exchange rate. International Economic Review. 47, 527-556.

Radice, M.P. (2010). Systemische Risiken im Versicherungssektor?. FINMA Working Paper.

Reboredo, J.C., \& Ugolini, A. (2015). Systemic risk in European sovereign debt markets: A CoVaRcopula approach. Journal of International Money and Finance, 51, 214-244. 
Schwarcz, D., \& Schwarcz, S.L. (2014). Regulating Systemic Risk in Insurance. 81 University of Chicago Law Review, 1569-1640.

Tang, Q., \& Yang, F. (2012). On the Haezendonck-Goovaerts risk measure for extreme risks. Insurance: Mathematics and Economics, 50(1), 217-227.

Wanat, S., Śmiech, S., \& Papież, M. (2016). In Serch of Hedges and Safe Havens in Global Financial Markets. Statistics in Transition. New Series, 17(3), 557-574.

Xie, X., \& Beni, G. (1991). Validity measure for fuzzy clustering. IEEE Transactions on Pattern Analysis and Machine Intelligence, 13, 841-847.

\section{Authors}

The contribution share of authors is equal and amounted to $50 \%$ each of them.

\section{Anna Denkowska}

Assistant Professor in the Mathematics Department of the Cracow University of Economics (Poland). MSc in mathematics (Jagellonian University), PhD in mathematics (Jagiellonian University). Her research interests include functional analysis, statistics, risk modelling, and network theory. Correspondence to: Dr Anna Denkowska, Cracow University of Economics, Department of Mathematics, Rakowicka 27, 31-510 Krakow, Poland, e-mail: anna.denkowska@uek.krakow.pl ORCID $\odot$ https://orcid.org/0000-0003-4308-8180

\section{Stanisław Wanat}

Associate Professor in the Mathematics Department at the Cracow University of Economics (Poland), MSc in mathematics (Jagiellonian University), PhD in economics (Cracow University of Economics), habilitation in economics (Cracow University of Economics). His research interests include statistics, actuarial methods, risk modelling, and forecasting.

Correspondence to: Prof. UEK, dr hab. Stanisław Wanat, Cracow University of Economics, Department of Mathematics, Rakowicka 27, 31-510 Krakow, Poland, e-mail: wanats@uek.krakow.pl ORCID (ㄱ) http://orcid.org/0000-0001-6225-4207

\section{Acknowledgements and Financial Disclosure}

This article was financed by the Ministry of Science and Higher Education of the Republic of Poland as part of a research program "Regional Initiative of Excellence" Programme for 2019-2022. Project no.: 021/RID/2018/19. Total financing: 11897131.40 PLN.

\section{Copyright and License}

This article is published under the terms of the Creative Commons Attribution - NoDerivs (CC BY-ND 4.0) License http://creativecommons.org/licenses/by-nd/4.0/

Published by Cracow University of Economics - Krakow, Poland 
